\title{
A study on specific absorption rate (SAR) due to non-ionizing radiation from wireless/telecommunication in Bangladesh
}

\author{
A K M Fazlul Hoque ${ }^{1}$, Md. Sazzad Hossain ${ }^{2}$, A Sattar Mollah ${ }^{3}$, Md. Akramuzzaman ${ }^{4}$ \\ ${ }^{1}$ Physics Department, Tejgaon College, Farmgate, Dhaka \\ ${ }^{2}$ Physics Department, National University, Gazipur, Bangladesh \\ ${ }^{3}$ Nuclear Safety and Radiation Control Division, Bangladesh Atomic Energy Commission, Dhaka \\ ${ }^{4}$ Physics Department, Jahangirnagar University
}

\section{Email address:}

fh2512@yahoo.com (A K M Fazlul Hoque), sazzad_iiuc@yahoo.com (Md. Sazzad Hossain), mollah_as@yahoo.com (A Sattar Mollah), akramuzzaman50@yahoo.com (Md. Akramuzzaman)

\section{To cite this article:}

A K M Fazlul Hoque, Md. Sazzad Hossain, A Sattar Mollah, Md. Akramuzzaman. A Study on Specific Absorption Rate (SAR) Due to Non-Ionizing Radiation from Wireless/Telecommunication in Bangladesh. American Journal of Physics and Applications.

Vol. 1, No. 3, 2013, pp. 104-110. doi: 10.11648/j.ajpa.20130103.18

\begin{abstract}
In the work exposure to the non-ionizing electro-magnetic radiation from some mobile cellular telephone operators and radio, TV and radar antennas of Bangladesh has been investigated. The mobile telephone operators considered were City cell, Grameenphone, Aktel and BanglaLink. The radio operators studied were 17 in number and all of them were sub stations of Bangladesh Radio. The TV antennas were all of BTV. Together with it 4 radar stations were also studied. The frequency range covered in the investigation is $800 \mathrm{MHz}$ to $2800 \mathrm{MHz}$. Calculations were done for specific absorption rate (SAR) and consequent rise of temperature in human tissues. Maximum power density value (for far field) observed is that for the BanglaLink operator $(=1.27 \times 10-6 \mathrm{~W} / \mathrm{m} 2)$. SAR values and the corresponding temperature rise were calculated for the eye, brain and nerve tissues exposed to RF fields, for the general public and occupational workers of Bangladesh for each of the mobile operators. Among the tissues, eye showed the highest and nerves the lowest SAR values. Of all the 4 operators Grameenphone possesses the highest SAR values (approximately $1.6 \mathrm{~W} / \mathrm{kg}$ ), still remaining within the FCC (Federal Communications Commission) and other safety limits (= $1.6 \mathrm{~W} / \mathrm{kg}$ ). Upto $960 \mathrm{MHz}$ of frequency the mobile operators of Bangladesh show higher SAR values compared to those of the literature. The RF radiation studied does not pose any health hazard for the general public. Temperature rise in 6 minutes time as a consequence of absorption of RF radiation from mobile operators is of the range $0.022 \mathrm{~K}$ to $0.763 \mathrm{~K}$
\end{abstract}

Keywords: Non-Ionizing Electro-Magnetic Radiation, Power Density, Specific Absorption Rate (SAR), Health Hazard, RF Radiation

\section{Introduction}

Scientific research into possible health effects has been unable to keep pace with the rapid advances in the applications of RF fields in our working and living environment. This delay has led to widespread concern among the general public and workforce and there remained unresolved health issues demanding to address them urgently. Much of this concern arises because new technologies are introduced without provision of public information about their nature or discussion of the debate within the scientific community about possible health consequences. Mobile phones are one such item. Industry sources suggest that there will be falling costs for mobile phones. These days use of these phones has increased dramatically with this falling cost.

Microwave radiation (MW) is absorbed near the skin, while radiofrequency radiation may be absorbed throughout the body. There are two sources of radio frequenscy (RF) exposure from the mobile phone system, base station antennas, and the mobile phone or handset. Exposure from the antennas is continuous, irradiates the whole body and exposes an entire community. Exposure from the handset to the head is more intense, is only for intermittent periods and tends to be of concern to the user. 
For analyzing absorption of energy by the human body, electromagnetic fields can be divided into four ranges [1]:

- Frequencies from about $100 \mathrm{kHz}$ to less than about $20 \mathrm{MHz}$, where absorption in the trunk decreases rapidly with decreasing frequency, and significant absorption may occur in the neck and legs;

- $\quad$ Frequencies in the range from about $20 \mathrm{MHz}$ to $300 \mathrm{MHz}$, at which relatively high absorption can occur in the whole body, and to even higher values if partial body (e.g., head) resonances are considered;

- $\quad$ Frequencies in the range from about $300 \mathrm{MHz}$ to several $\mathrm{GHz}$, at which significant local, nonuniform absorption occurs. Frequencies above about $10 \mathrm{GHz}$, at which energy absorption occurs primarily at the body surface.

A CDMA phone transmits with an average power of $200 \mathrm{~mW}$, the power varying depending on the quality of communication with the base station. Multiple users are accommadated by transmitiing the signal over a wide spectrum (spread spectrum) and applying digital codes to the data. The mobile phone uses the code to distinguish its intended message from other users. All users share the same range of radio spectrum. This technique permits more users in a given cell than for an equivelant GSM site and in general results in lower exposures from base stations than from GSM sites.

When a GSM digital phone is transmitting, the signal is time shared with seven other users. This means that in any one second each of the eight users on the same frequency is allotted $1 / 8$ of the time and the signal is reconstituted by the receiver to form speech. In order to limit interference between neighboring cells mobile phones are designed to use the minimum power necessary to maintain communication. Peak power output corresponds to 2 Watts or 2000 milliwatts (mW) which averages to $250 \mathrm{~mW}$ of continuous power.

Specific absorption rate (SAR) $[\mathrm{W} / \mathrm{kg}]$ describes the possible biological effects of RF fields. The high energy of RF field exposure causes thermal effects in biological tissues and generates high SAR values. However, the socalled non-thermal effects, or the biological effects of RF fields at low energy levels have not been clarified yet.

The basic concern of the present work is health hazard. Let's now discuss about the radiation effect. The depth of penetration is more in the child than the adult. The exposure of high intensity electromagnetic waves in the ultra high frequency (i.e., $300 \mathrm{MHz}-3 \mathrm{GHz}$ ) range generates heat, which can cause thermal damage to the brain, specially of the children. This temperature may rise upto about $0.10 \mathrm{C}$ in $1 \mathrm{~mm} 3$ after $33 \mathrm{hr}$ of continuous phone use. DNA breaks after receiving RF exposure.

Regarding the RF based facilities; we should have a national plan so that the SAR values for each of them available in the market be estimated for its onward publication. In general, exposure to a uniform (plane wave) electromagnetic field results in a highly non-uniform deposition and distribution of energy within the body. This can be assessed by dosimetric measurement, as well as through calculation. Currently the guidelines for mobile phones in most of the countries are given by local exposure limits. The limits are, however, not harmonized yet. The USA, Japan, Canada, Korea, China etc have set their limits. Bangladesh has not yet done so. The present work has been taken in this line so as to have some contribution in this regard. The present work derives the necessary empirical equation for calculation of SAR and to have an idea about the rise of temperature

\section{Electromagnetic Field Interactions with Biological Systems}

The interaction of electromagnetic field and radiation with biological systems is characterized by the electromagnetic properties of tissue media, more specifically, the permittivity. The permittivity of biological materials displays unique dependence on frequency [2]. However, an increase of the permeability of the BBB resulted when the brain average SAR was $25 \mathrm{~W} / \mathrm{kg}$ as a result of the thermal effects of the exposure [3].

Mentioning the results of some in vitro experiment is worth, when talking about the effects of EM field and radiation with biological systems. These experiments were designed [4] for investigation of acute effects of 1,765 $\mathrm{MHz}$ RF wave. Two kinds of human cells (Jurkat human T lymphomia cell and WI-38 human fibroblast) and 2 kinds of mouse cells were exposed at $1.5 \mathrm{~W} / \mathrm{kg}$ and $75 \mathrm{~W} / \mathrm{kg} \mathrm{SAR}$ for $30 \mathrm{~min}$. and $12 \mathrm{hrs}$.

Some additional observations in this regard are as follows [5]:

a. Stimulation effect prevails over other possible effects in the low frequency region (up to 100 $\mathrm{kHz}$ ), where the induced current density, J $\left(\mathrm{A} / \mathrm{m}^{2}\right)$ in tissue is the dosimetric quantity.

b. In higher frequencies above $10 \mathrm{MHz}$ up to 300 $\mathrm{GHz}$, thermal effects are prominent. SAR is the quantity to define the dose at frequencies from $100 \mathrm{kHz}$ to about $10 \mathrm{GHz}$. Incident power density in terms of watt per square meter $\left[\mathrm{W} / \mathrm{m}^{2}\right]$ is more appropriate than SAR at frequencies above $10 \mathrm{GHz}$, where the penetration of EMF into skin is very short. Thermal effects and stimulation effects could overlap each other in the intermediate frequencies between $100 \mathrm{kHz}$ and $10 \mathrm{MHz}$.

\section{Specific Absorption Rate (SAR)}

SAR values depend on the sizes and shapes of the organ. Pack and Lee [6] carried out an investigation on it and calculated the local SAR values for different head sizes and shapes using the Finite Difference Time Domain (FDTD) 
method for mobile phone frequencies of 835 and 1,765 $\mathrm{MHz}$.

Exposure limits for mobile phone of most of the organizations and countries are based on well-understood thermal effect. During using a mobile phone the temperature rises in human body due to exposure from strong EMF source. Hazards of exposure to high levels of RF fields, which result in tissue heating, are basically understood, although there are still a number of unresolved issues concerning it. Aiming at reducing the gaps in knowledge on health effect of long term low level exposure, WHO's International EMF Projects are focused on [7] investigating the:

a. Biological effects of long term exposure in 900$2000 \mathrm{MHz}$ frequency band used in mobile or cellular phone systems with exposure levels lower than exposure limits, which include cancer related studies,

b. studies on changes in hormone levels, memory loss, neurodegenerative disease, effects on the ear and eye, etc.

Experimental approaches are being applied in the measurements of SAR. In such method tissue equivalent "phantoms" are used instead of real bodies in the experimental dosimetry. Thermo-graphic method directly measures temperature elevation due to absorbed energy in the exposed object to RF range.

In tissue, SAR is proportional to the square of the internal electric field strength. Values of SAR depend on the following factors:

- the incident field parameters, i.e. the frequency, intensity, polarization, and source object configuration (near field or far field);

- the characteristics of the exposed body, i.e. its size, internal and external geometry, and the dielectric properties of the various tissues;

- reflection, absorption and scattering effects associated with the ground or other objects in the field near the exposed body.

At distances within a wavelength from a RF transmitter is a region known as the near field. Since mobile phone radiation has a wavelength of $30 \mathrm{~cm}$ at $900 \mathrm{MHz}$ (GSM phone) the user's head will be within this near field region. The head disturbs the field and alters the manner in which RFR interacts with tissue. This interaction complicates the absorption of RF energy within the head and makes calculations difficult. Absorptions within the head are therefore determined experimentally or by simulation on a computer.

\section{Electromagnetic Fields and SAR}

In accordance with Faraday's law [8], magnetic fields that vary in time induce the movement of electrical charge and cause potentials and circulating (eddy) currents in biological systems. These currents can be estimated using the following equation, provided that the current paths are circular:

$$
\mathrm{J}=\sigma \mathrm{E}=0.5 \mathrm{r} \sigma(\partial \mathrm{B} / \partial \mathrm{t})
$$

where:

$\mathrm{J}=$ current density $\left(\mathrm{A} / \mathrm{m}^{2}\right)$

$\mathrm{E}=$ induced electric field strength $(\mathrm{V} / \mathrm{m})$

$\mathrm{r}=$ radius of the loop $(\mathrm{m}$ ) (usually several $\mathrm{cm}$ up to 20 $\mathrm{cm})$

$\sigma($ sigma $)=$ tissue conductivity $(\mathrm{S} / \mathrm{m})$

$\partial \mathrm{B} / \partial \mathrm{t}=$ rate of change of magnetic flux density $\mathrm{B}(\mathrm{T} / \mathrm{s})$.

For sinusoidal fields of frequency $\mathrm{f}$, the above equation reduces to:

$$
J=\pi r \sigma \mathrm{fB}_{0}
$$

where $\mathrm{B}_{0}$ is the magnetic flux density peak amplitude. The current density, internal electric field, and SAR, at any location in an exposed biological body, are inter-related as follows:

$$
\mathrm{SAR}=\sigma \mathrm{E}^{2} / \rho
$$

where, $\rho($ rho $)$ is the physical density $\left(\mathrm{kg} / \mathrm{m}^{3}\right)$ and

$$
\mathrm{SAR}=\mathrm{J}^{2} / \sigma \rho
$$

A direct calculation of the expected temperature rise $(\delta \mathrm{T}$ in Kelvin) in tissue exposed to RF fields for a time ( $t$ seconds) can be made from the equation:

$$
\delta \mathrm{T}=(\mathrm{SAR}) \mathrm{t} / \mathrm{C}
$$

where $\mathrm{C}$ is the specific heat capacity expressed in $\mathrm{J} / \mathrm{kg} \mathrm{K}$. This equation, however, does not include terms to account for heat losses via processes such as thermal conduction and convection.

\section{Results and Discussion}

The investigation reported in this work has been carried out on pacific bangladesh telecom limited (PBTL - City Cell), grameenphone, aktel, banglalink, the TV stations/centres in Bangladesh, the radio stations and the radar stations/centres. On each of these operators, alongwith the general survey of the stations/centers, the measurements were carried out on the SAR values. In the work SAR values and the corresponding temperature rise for 6 minutes duration have been calculated using equations (1-5) respectively for three different tissues, e.g., eye, brain and nerve exposed to RF fields. Equation shows that SAR is directly proportional to the conductivity in the radiated tissue and inversely proportional to the physical density of it. As these characteristics are different for the different tissues, the SAR values for them have varied.

The relevant data describing the physical properties of human tissue and electrode material: density, $\rho$, specific heat, $\mathrm{C}$, and conductivity, $\sigma$ are collected from available source. Again since the conductivity and the density are constant for a particular tissue and a particular radiation 
type having a definite frequency, the SAR value should then depend mainly on the induced electric field produced from EMF. More specifically it (SAR) is proportional to the square of the intensity of the induced electric field and is inversely proportional to the square of distance from the source to the tissue element. Tables 1 and 2 show the results for SAR and $\delta \mathrm{T}$, respectively for the general public and occupational workers. Fig. 1 shows the results obtained for the tissues nerve, brain and eye for both the general public and occupational workers.

Table 1 Calculation of SAR and temperature change (ST) for the general public through assessment of electric field

\begin{tabular}{|c|c|c|c|c|c|c|}
\hline $\begin{array}{l}\text { Tissue } \\
\text { type }\end{array}$ & $\begin{array}{c}\text { Density } \\
\rho \\
{\left[\mathrm{kg} / \mathrm{m}^{3}\right]}\end{array}$ & $\begin{array}{c}\text { Frequency } \\
\text { [MHz] }\end{array}$ & $\begin{array}{c}\text { Conductivity, } \\
\sigma \\
{[\mathbf{S} / \mathbf{m}]}\end{array}$ & $\begin{array}{c}\text { Electric field } \\
\text { strength, } E[V / m]\end{array}$ & $\begin{array}{c}\text { SAR } \\
{[\mathbf{W} / \mathbf{k g}]}\end{array}$ & $\begin{array}{c}\text { Temp. change } \\
\delta \mathrm{T} \\
{[\mathrm{K}]}\end{array}$ \\
\hline \multirow{5}{*}{ Nerve } & \multirow{5}{*}{1040} & 800 & 0.16 & 38.89 & 0.232 & 0.022 \\
\hline & & 850 & 0.17 & 40.08 & 0.262 & 0.025 \\
\hline & & 900 & 0.18 & 41.25 & 0.294 & 0.028 \\
\hline & & 950 & 0.19 & 42.38 & 0.328 & 0.032 \\
\hline & & 1000 & 0.195 & 43.48 & 0.354 & 0.034 \\
\hline \multirow{5}{*}{ Brain } & \multirow{5}{*}{1040} & 800 & 0.54 & 38.89 & 0.785 & 0.077 \\
\hline & & 850 & 0.58 & 40.08 & 0.895 & 0.088 \\
\hline & & 900 & 0.62 & 41.25 & 1.014 & 0.099 \\
\hline & & 950 & 0.65 & 42.38 & 1.122 & 0.110 \\
\hline & & 1000 & 0.67 & 43.48 & 1.217 & 0.119 \\
\hline \multirow{5}{*}{ Eye } & \multirow{5}{*}{1170} & 800 & 0.82 & 38.89 & 1.059 & 0.104 \\
\hline & & 850 & 0.88 & 40.08 & 1.208 & 0.118 \\
\hline & & 900 & 0.93 & 41.25 & 1.352 & 0.132 \\
\hline & & 950 & 0.97 & 42.38 & 1.489 & 0.146 \\
\hline & & 1000 & 1.01 & 43.48 & 1.631 & 0.160 \\
\hline
\end{tabular}

* Specific heat, $\mathrm{C}=3664[\mathrm{~J} /(\mathrm{kg} \mathrm{K})] \quad * *$ Time duration, $\mathrm{t}=360 \mathrm{sec}$.

Table 2 Calculation of SAR and temperature change ( $\delta T)$ for the occupational worker through assessment of electric field

\begin{tabular}{|c|c|c|c|c|c|c|}
\hline $\begin{array}{l}\text { Tissue } \\
\text { Type }\end{array}$ & $\begin{array}{c}\text { Density } \\
\rho \\
{\left[\mathrm{kg} / \mathrm{m}^{3}\right]}\end{array}$ & $\begin{array}{c}\text { Frequency } \\
{[\mathrm{MHz}]}\end{array}$ & $\begin{array}{c}\text { Conductivity, } \\
\sigma \\
{[\mathrm{S} / \mathrm{m}]}\end{array}$ & $\begin{array}{c}\text { Electric field } \\
\text { strength, } E[\mathrm{~V} / \mathrm{m}]\end{array}$ & $\begin{array}{c}\text { SAR } \\
{[\mathrm{W} / \mathrm{kg}]}\end{array}$ & $\begin{array}{c}\text { Temp. } \\
\text { change } \delta \mathrm{T} \\
{[\mathrm{K}]}\end{array}$ \\
\hline \multirow{5}{*}{ Nerve } & \multirow{5}{*}{1040} & 800 & 0.16 & 84.85 & 1.107 & 0.108 \\
\hline & & 850 & 0.17 & 87.46 & 1.250 & 0.122 \\
\hline & & 900 & 0.18 & 90.00 & 1.401 & 0.137 \\
\hline & & 950 & 0.19 & 92.46 & 1.561 & 0.153 \\
\hline & & 1000 & 0.195 & 94.86 & 1.687 & 0.165 \\
\hline \multirow{5}{*}{ Brain } & \multirow{5}{*}{1040} & 800 & 0.54 & 84.85 & 3.738 & 0.367 \\
\hline & & 850 & 0.58 & 87.46 & 4.265 & 0.419 \\
\hline & & 900 & 0.62 & 90.00 & 4.828 & 0.474 \\
\hline & & 950 & 0.65 & 92.46 & 5.343 & 0.524 \\
\hline & & 1000 & 0.67 & 94.86 & 5.797 & 0.569 \\
\hline \multirow{5}{*}{ Eye } & \multirow{5}{*}{1170} & 800 & 0.82 & 84.85 & 5.045 & 0.495 \\
\hline & & 850 & 0.88 & 87.46 & 5.753 & 0.565 \\
\hline & & 900 & 0.93 & 90.00 & 6.438 & 0.632 \\
\hline & & 950 & 0.97 & 92.46 & 7.087 & 0.696 \\
\hline & & 1000 & 1.01 & 94.86 & 7.767 & 0.763 \\
\hline
\end{tabular}

* Specific heat, $\mathrm{C}=3664[\mathrm{~J} /(\mathrm{kg} \mathrm{K})] \quad * *$ Time duration, $\mathrm{t}=360 \mathrm{sec}$. 


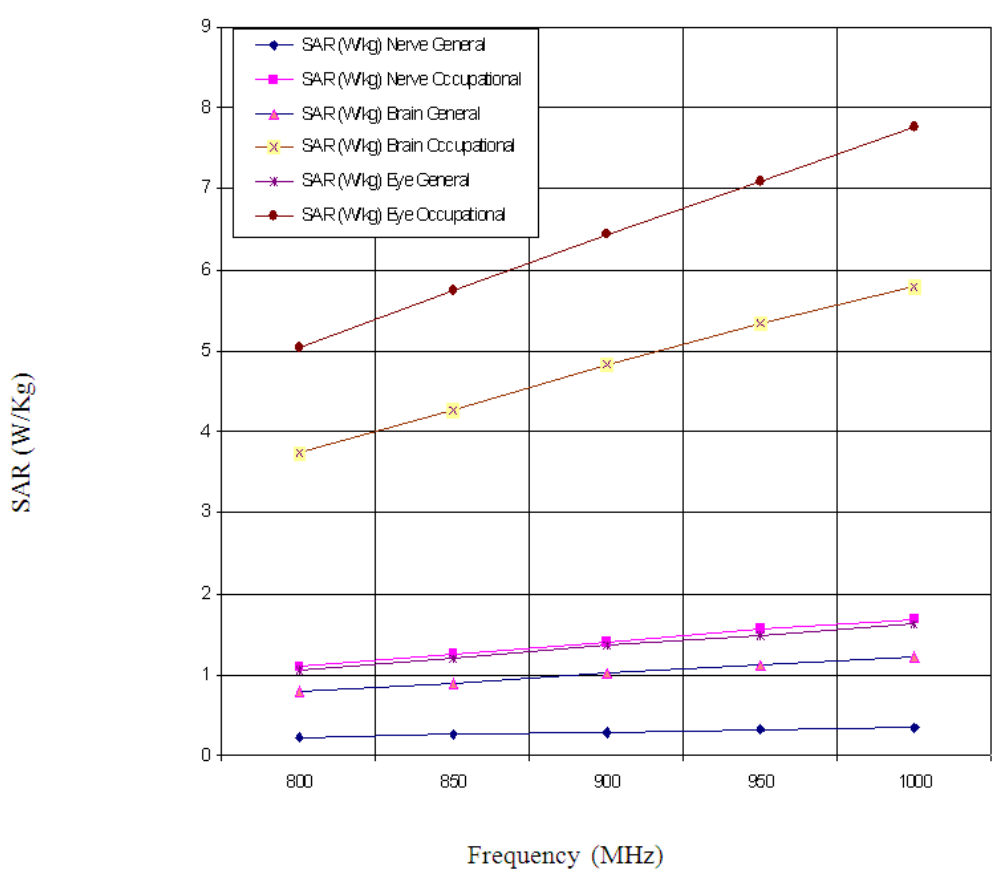

Fig. 1 Variation of SAR values with radiation frequency for different tissues for occupational and general public

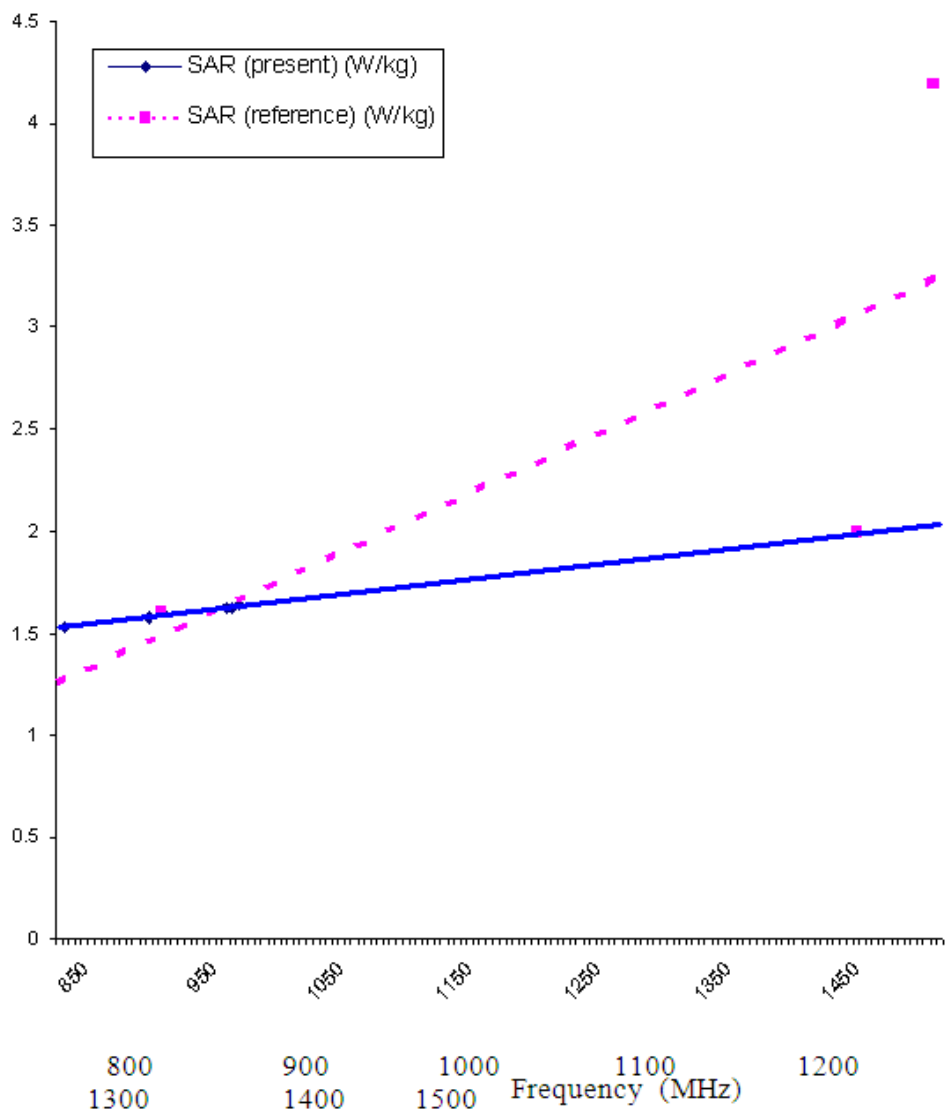

Fig. 2 Comparison of SAR values

\subsection{Comparison of the SAR Values}

Table 3 contains the extracted results on the present SAR values along with the literature values quoted beside for a comparison. Two values for each mobile company, e.g., the minimum and the maximum are considered for this comparison. Fig. 1 shows the calculated values of SAR from the present work along with the reference values as obtained from literature $[9,10]$. From this graph one can see that reference SAR line is steeper compared to the one having the local SAR values. 
Table 3 Calculated values and literature values of SAR

\begin{tabular}{|c|c|c|c|c|c|c|c|}
\hline \multirow[b]{2}{*}{$\begin{array}{c}\text { Frequency } \\
(\mathrm{MHz})\end{array}$} & \multicolumn{4}{|c|}{ Calculated values in Bangladesh } & \multicolumn{3}{|c|}{ Values from literature [12] } \\
\hline & $\begin{array}{l}\text { Conduc. } \\
(\mathrm{S} / \mathrm{m})\end{array}$ & $\begin{array}{c}\text { Induced } \\
\text { Electric } \\
\text { Field, E } \\
(\mathrm{V} / \mathrm{m}) \\
\end{array}$ & $\begin{array}{c}\text { SAR } \\
(\mathrm{W} / \mathrm{kg})\end{array}$ & $\begin{array}{l}\text { Temp. } \\
\text { Change } \\
\text { (K) }\end{array}$ & $\begin{array}{l}\text { SAR } \\
(\mathrm{W} / \mathrm{kg})\end{array}$ & $\begin{array}{c}\text { Conduc. } \\
\sigma \\
(\mathrm{S} / \mathrm{m})\end{array}$ & $\begin{array}{c}\text { IEF, } \\
\text { E } \\
(\mathrm{V} / \mathrm{m})\end{array}$ \\
\hline 825 & 1.570 & 31.80 & 1.53 & 0.183 & & & \\
\hline 835 & & & & & & 0.921 & \\
\hline 890 & 1.590 & 32.10 & 1.58 & 0.189 & & & \\
\hline 898 & 1.596 & 32.15 & 1.59 & 0.190 & & & \\
\hline 900 & 1.600 & 32.20 & 1.60 & 0.191 & 1.6 & 1.6 & $32.3(6 \mathrm{~min})$ \\
\hline 915 & & & & & & 1.6 & \\
\hline 950 & 1.610 & 32.30 & 1.62 & 0.194 & & & \\
\hline 955 & 1.615 & 32.32 & 1.62 & 0.195 & & & \\
\hline 960 & 1.620 & 32.40 & 1.64 & 0.196 & & & \\
\hline 1439 & & & & & 0.99 & 1.70 & 24.6 (1h 4 week) \\
\hline 1440 & & & & & 7.5 & 1.70 & 67.7 (whole body) \\
\hline 1450 & & & & & 1.7 & 1.70 & 32.3 (4h one time) \\
\hline 1455 & & & & & 2.0 & 1.70 & 35.0 (whole body) \\
\hline 1470 & & & & & 25 & 1.70 & 123.7(whole body) \\
\hline 1480 & & & & & 4.5 & 1.70 & 52.5 (1h/d 1 day) \\
\hline 1490 & & & & & 7.5 & 1.70 & 67.7 (1h/d 4 day) \\
\hline 1495 & & & & & 1.6 & 1.70 & 31.3 (Canada) \\
\hline 1500 & & & & & 20 & 1.70 & 110.6 (Japan, EU) \\
\hline 1500 & & & & & 4.2 & 1.77 & 49.7 (6 min) \\
\hline 1765 & & & & & & 1.417 & \\
\hline 2040 & & & & & 0.9869 & 2.10 & 22.10 \\
\hline 2040 & & & & & 0.453 & 2.10 & 15.0 \\
\hline 2050 & & & & & & 2.21 & \\
\hline 2800 & 2.230 & 42.00 & 3.78 & 0.454 & & & \\
\hline 2810 & 2.235 & 42.10 & 3.80 & 0.457 & & & \\
\hline 3000 & & & & & 10 & 2.24 & $68.1 / 30.5(6 \mathrm{~min})$ \\
\hline 3100 & & & & & 20 & 2.24 & $96.4 / 43.1(6 \mathrm{~min})$ \\
\hline
\end{tabular}

The local values are larger than the literature values upto $950 \mathrm{MHz}$, above this point the reference values exceed the local SAR values. Implication of these higher values above $950 \mathrm{MHz}$ is important. In Bangladesh the mobile telephone operators work in the frequency range 825 to $960 \mathrm{MHz}$; higher frequency values are being operated upon by other RF operators, such as radar. The SAR for radar in our country is less than the reference values; where as, on the other hand, our mobile operators produce larger SAR values compared to that in the reference.

A point is very important and worth mentioning - SAR values are heavily dependent on the size of the averaging volume. Without information about the averaging volume used comparisons between different measurements cannot be made. In this context the comments made in the previous paragraph can be adjudged as a gross one only. The figure also indicates that the SAR values - both the reference and local ones increase linearly with RF wave frequencies.

\subsection{The SAR Values and Probable Health Hazard}

Chiang [11] in his study suggests that SAR should be less than $0.02 \mathrm{~W} / \mathrm{kg}$ for general population and less than 0.1 $\mathrm{W} / \mathrm{kg}$ for occupational workers. In the work the author showed his experimental evidence on the point that for SAR exposure range $1.0 \mathrm{~W} / \mathrm{kg}$ to $1.2 \mathrm{~W} / \mathrm{kg}$, chromosome aberration happens resulting in the damage of DNA. Research from Greece towards the end of 2006 found a direct causal relationship between mobile phone radiation and DNA damage. In December 2004 a pan-European study named REFLEX (Risk Evaluation of Potential Environmental Hazards from Low Energy Electromagnetic Field (EMF) Exposure Using Sensitive in vitro Methods), 
involving 12 collaborating laboratories in several countries showed some compelling evidence of DNA damage of cells in in-vitro cultures, when exposed between 0.3 to 2 watts $/ \mathrm{kg}$, whole-sample average. There were indications, but not rigorous evidence of other cell changes, including damage to chromosomes, alterations in the activity of certain genes and a boosted rate of cell division. In the present calculations SAR values came around $1.5 \mathrm{~W} / \mathrm{kg}$ for the general population at the specific operating frequencies of RF waves from the mobile phones in Bangladesh.

\section{Conclusions}

Calculations were done for specific absorption rate (SAR) and consequent rise of temperature in human tissues. SAR values and the corresponding temperature rise were calculated for the eye, brain and nerve tissues exposed to RF fields, for the general public and occupational workers of Bangladesh for each of the mobile operators. Among the tissues, eye showed the highest and nerves the lowest SAR values. Of all the 4 operators Grameenphone possesses the highest SAR values $(=1.6 \mathrm{~W} / \mathrm{kg})$, still remaining within the FCC (Federal Communications Commission) and other safety limits $(=1.6 \mathrm{~W} / \mathrm{kg})$. Upto $960 \mathrm{MHz}$ of frequency the mobile operators of Bangladesh show higher SAR values compared to those of the literature. The RF radiation studied does not pose any health hazard for the general public. Temperature rise in 6 minutes time as a consequence of absorption of RF radiation from mobile operators is of the range 0.022 to $0.763 \mathrm{~K}$. On the basis of the extracted information, a set of recommendations has been proposed in the work for reduction of the SAR on human tissues.

The observed SAR and power density values due to the radar antenna could not be compared with any other results because of non-availability of any such related data. In order to ensure safety of the general people from possible health hazard the danger area around radio, TV, radar antennas should be properly fenced and be marked with appropriate radiation caution signs. In order to reduce exposure to human head, monopole antenna might be mounted on printed circuit board in the opposite side of ear piece for mobile phone. Because internal printed circuit board plays a role on reflection plate, the resonance of antenna would be disappeared. Thus, electromagnetic absorber is inserted between printed circuit board and internal monopole antenna for SAR reduction and antenna resonance, which absorbs electromagnetic waves toward human body generated from mobile phone and prevents distortion for the resonance of proposed antenna.

From the end of the users the steps may be taken for reducing SAR values are minimization of cell phone usage, limitation of use by at-risk population (such as children), adoption of cell phones and micro cells with ALARA levels of radiation, wider use of handsoff and earphone technologies such as Bluetooth headsets, adoption to maximal standards of exposure, RF field intensity and distance of base stations antennas from human habitations, and so forth. "Hands' free" kits with ear pieces can be used with cell phones for convenience and comfort

\section{References}

[1] ICNIRP, Guidelines on limits of exposure to time-varying electric, magnetic and electromagnetic fields (up to $300 \mathrm{GHz}$ ). International Commission on Non-Ionizing Radiation. Health Physics 74: 494-522, 1998.

[2] Ueno, S. et al. Experimental difficulties in observing the effects of magnetic fields on biological and chemical processes. IEEE Trans. Mag. 22(5): 868-873, 1986.

[3] Yamaguchi, et al., Effects of exposure to high-frequency electromagnetic waves on rat-reference memory in a T-maze task, $23^{\text {rd }}$ Annual meeting of the Bioelectromagnetics Society, St. Paul, Minn, June 12, 2001.

[4] A. K. Lee et. al., "Electromagnetic Energy absorption in a human head for a cellular phone at $835 \mathrm{MHz}$," Proceedings of 1998 APMC (Asia-Pacific Microwave Conference), Vol. 2, pp $873-876$.

[5] IEEE/ANSI Standards for safety levels with respect to human exposure to radiofrequency electromagnetic fields, 3 $\mathrm{kHz}$ to $300 \mathrm{GHz}$. (Standard C95. 1-1991) Inst. Elec. Electro. Engineers (1992).

[6] A. K. Lee et. al. "Effect of head size for cellular telephone exposure on EM absorption," Submitted to IEICE Trans. On Comm.

[7] Y.O. Ahn et al., "Cross-sectional symptom survey for investigation of health-effect of mobile-phone EMF," KEES, vol. 12, no. 2, 2001.

[8] Epstein, B.R. \& Foster, K.R. Anisotropy in the dielectric properties of skeletal muscle. Med. Biol. Eng. Comput.,21:25-55.1983.

[9] Herman Cember, Northwest University, "Introduction to Health Physics", Second Edition, McGRAW-HILL, INC. Pergamon Press, Inc.

[10] WHO Meeting on EMF Biological Effects and standards Harmonization in Asia and Oceania. 22-24 October, 2001, Shilla Hotel, Seoul, Korea.

[11] Chiang, B.J. Shao, N.G. Wu, R.Y., H. Li, and Y.D. Fu Effects of $2.45-\mathrm{GHz}$ microwave radiation and phorbolester 12-0-tetra-decanoylphorbol-1 3-acetate on dimethylhydrazine-induced colon cancer in mice, Bioelectromagnetics, Vol. 15, No. 6, pp. 531-538,1994.

[12] Herman Cember, Northwest University, "Introduction to Health Physics", Second Edition, McGRAW-HILL, INC. Pergamon Press, Inc. 